\title{
Applicability of the contingent valuation method to cost-benefit analysis for rural parks
}

\author{
Y. Kunimitsu \\ Department of Rural Planning, \\ National Institute for Rural Engineering, Japan
}

\begin{abstract}
Rural parks are public projects that need to be evaluated by cost-benefit analysis, but this is difficult due to the lack of market value. This paper evaluates the applicability of the contingent valuation method (CVM) by analyzing the relation between benefits of the park and visitation range. Evaluation models for willingness-to-pay (WTP) were modified with consideration of visitation behaviour of residents estimated by the gravity model. The results indicate that: (1) benefits evaluated by the WTP value decrease with distance, not because of a decreasing tendency in the WTP value itself, but because of a decline in visitation frequency influenced by distance; and (2) benefits of all residents increased because of a rise in the number of non-visitors when the researchers set the survey range wider, however, benefits evaluated by visitors' WTP converged to a constant level at a certain range. Therefore, the critical factor for applying the CVM to a cost-benefit analysis with stability is to exclude, or to control, the WTP value of non-visitors, especially non-visitors outside of the feasible visitation range.
\end{abstract}

Keywords: gravity model, visitation frequency, visitation range, willingness-topay (WTP).

\section{Introduction}

Rural parks have been constructed as public projects by local governments in the countryside. Green fields, walking tracks, and irrigation canals similar to natural creeks are constructed in the park to improve amenities relating to the rural landscape and living environment, as well as to preserve the natural environment and wildlife. 
In terms of public projects, cost-benefit analysis is required to proof efficiency of the project (Willis [11]). Since benefit of public project is difficult to evaluate from market value, the travel cost method (TCM) and the contingent valuation method (CVM) are usually applied for evaluation. However, travel data of residents are hardly obtained at planning stage before construction, so that CVM is considered to be the most applicable method for benefit calculation.

In the field of environmental economics, CVM has been used for evaluation of environmental function (Kerr [4], Kunimitsu et al. [5]) and food safety issues (Bennett et al. [1], Kaye-Blake et al. [3]). However, there were few studies on analyzing the WTP value by visitation frequency group and distance from the park. Some studies even found opposite effects of distance on the WTP value, showing both positive (Yoshida et al. [10]) and negative effects (Talen and Anselin [8]), not indicating consistent tendency. Consequently, there is inconsistency of which wider setting of research area causes greater benefit.

The present study aims to evaluate the applicability of the CVM to costbenefit analysis. Especially, we focus on how WTP value is affected by the distance from the park, how WTP values are varied by the visitation frequency, and how to stabilize the cost-benefit ratio. To analyze above issues, pooled data from several sites of the similar parks were used and data were classified by the visitation frequency groups in order to see the difference in evaluation values.

\section{Methodology}

\subsection{Survey design}

To treat heterogeneity in visitation frequency, the WTP functions are estimated after classifying data by visitation frequency groups: fairly frequent visitors, G3, who visit the park more than 24 times a year (more than once for two weeks); frequent visitors, G2, who visit the park 6-23 times a year (more than once for two months); infrequent visitors, G1, who visit the park less than six times a year; and non-visitors, G0. The assumption about this classification was that residents can choose one of four rough division groups, even if residents cannot answer the precise number of visitation.

The following (hypothetical) question was asked to residents at each project site to estimate the WTP value. "If the park were completely managed and constructed by payments from residents, and you failed to pay, the park would soon be ruined, with no funds for maintenance and renovation. Would your household agree to an annual payment of 'B yen/year/household' as long as your family remains in the same situation as at present?" Here, $B$ is the proposed price in six different bands. Each resident was assigned one of the price sets at random.

A simple "yes-no" binary question was used to help residents decide easily whether the proposed price sounded reasonable. Each resident was then asked a second discrete-choice question depending on the response to the first question to improve the estimation efficiency (Hanemann et al. [2]). For residents who 
accepted the first proposed price $\left(B_{1}\right)$, a second price $\left(B_{2}{ }^{U}\right)$ higher than the first was proposed. For residents who denied $B_{1}$, a second price $\left(B_{2}^{D}\right)$ lower than the first was proposed.

\subsection{Models}

The true WTP value is assumed to be described by observable factors, $\mathbf{X}$ (attributes of residents and attributes of the park), distance $L$ from the park to the residential area defining the beneficial zone of the park, and by further unobservable factors, $\mu$. That is, $W T P=f(L, \mathbf{X})+\mu$. Gothic characters indicate the vector. To treat unobservable factors, the WTP function is modified to a probability function using the cumulative density function $F$. Consequently, the probabilities of different answers, $\pi_{y y}^{C}, \pi_{y n}^{C}, \pi_{n y}^{C}$, and $\pi_{n n}^{C}$, to the hypothetical question by residents are defined as follows:

(Both answers were "yes")

$$
\pi_{y y}^{c}=\operatorname{Pr}\left(B_{2}^{U} \leq W T P\right)=1-F\left[\frac{\alpha L+\mathbf{X} \boldsymbol{\beta}+\gamma \ln \left(B_{2}^{U}\right)}{\left(1+\mathbf{Z} \boldsymbol{\delta}^{C}\right)}\right],
$$

(The first answer was "yes" and the second answer was "no")

$$
\begin{aligned}
\pi_{y n}^{c}=\operatorname{Pr}\left(B_{1} \leq\right. & \left.W T P \leq B_{2}^{U}\right) \\
& =F\left[\frac{\alpha L+\mathbf{X} \boldsymbol{\beta}+\gamma \ln \left(B_{2}^{U}\right)}{\left(1+\mathbf{Z} \boldsymbol{\delta}^{C}\right)}\right]-F\left[\frac{\alpha L+\mathbf{X} \boldsymbol{\beta}+\gamma \ln \left(B_{1}\right)}{\left(1+\mathbf{Z} \boldsymbol{\delta}^{C}\right)}\right],
\end{aligned}
$$

(The first answer was "no" and the second answer was "yes")

$$
\begin{aligned}
\pi_{n y}^{c}=\operatorname{Pr}\left(D_{n y}=1\right)=\operatorname{Pr}\left(B_{2}^{D} \leq W T P \leq B_{1}\right) \\
=F\left[\frac{\alpha L+\mathbf{X} \boldsymbol{\beta}+\gamma \ln \left(B_{1}\right)}{\left(1+\mathbf{Z} \boldsymbol{\delta}^{C}\right)}\right]-F\left[\frac{\alpha L+\mathbf{X} \boldsymbol{\beta}+\gamma \ln \left(B_{2}^{D}\right)}{\left(1+\mathbf{Z} \boldsymbol{\delta}^{C}\right)}\right], \text { and }
\end{aligned}
$$

(Both answers were "no")

$$
\pi_{n n}^{c}=\operatorname{Pr}\left(W T P \leq B_{2}^{D}\right)=F\left[\frac{\alpha L+\mathbf{X} \boldsymbol{\beta}+\gamma \ln \left(B_{2}^{D}\right)}{\left(1+\mathbf{Z \delta}^{C}\right)}\right]
$$

Here, $D_{y y}, D_{y n}, D_{n y}$, and $D_{n n}$ are binary-valued indicator variables, equal to one if the $i$ th individual gives the responses indicated by the suffix, and zero otherwise. The symbol $\sigma$ denotes the standard deviation of $\mu$. This can be defined as $\sigma^{C}=\sigma^{C}{ }_{1}\left(1+\mathbf{Z}^{C} \boldsymbol{\delta}^{C}\right)$ with the benchmark value $\sigma^{C}$ and heterogeneity term $\mathbf{Z \delta}^{C}$ (Kunimitsu [7]). The parameter vector, $\boldsymbol{\delta}^{\mathrm{C}}$, of the site dummy variables, $\mathbf{Z}$, will be statistically significant if the standard deviation of a certain site differs from the bench mark site- site no. 1 in this model.

If $F$ in Eq. (1) is taken as the logistic distribution, the acceptance probability, $\pi^{C}(B)$, for proposed price, $B$, can be defined as:

$$
\pi^{C}(B, L, \mathbf{X}, \mathbf{Z})=1-1 / 1+\exp \left[\{\alpha L+\mathbf{X} \boldsymbol{\beta}+\gamma \ln (B)\} /\left(1+\mathbf{Z} \boldsymbol{\delta}^{C}\right)\right]
$$


Parameters $\alpha, \boldsymbol{\beta}, \gamma$, and $\boldsymbol{\delta}$ can be estimated by maxim likelihood method. Since data are classified into four visitation frequency groups, four values of each parameter are estimated from the grouped data; that is, $\alpha_{k}, \boldsymbol{\beta}_{k}, \gamma_{k}$, and $\boldsymbol{\delta}^{\mathbf{C}}{ }_{k}(k=0,1$, 2 , and 3 ).

To find the causative factors on visitation frequency, the probabilistic gravity type model was employed in this study. The probability, $\pi_{k}^{V}$, of each resident falling into the $k$ th visitation group rather than other groups can be defined as follows if the stochastic affect in classification is independent identically distributed as a logistic distribution.

$$
\pi_{k}^{V}=\frac{\exp \left\{\left(\alpha_{k}^{\prime} L_{k}+\mathbf{X}_{k} \boldsymbol{\beta}_{k}\right) /\left(1+\mathbf{Z} \boldsymbol{\delta}^{V}\right)\right\}}{1+\sum_{j=1}^{3} \exp \left\{\left(\alpha_{j}^{\prime} L_{j}+\mathbf{X}_{j} \boldsymbol{\beta}_{j}^{\prime}\right) /\left(1+\mathbf{Z} \boldsymbol{\delta}^{V}\right)\right\}} \quad, j, \text { and } k=1,2 \text { and } 3
$$

Here, $L$ and $\mathbf{X}$ show distance, and the attributes of residents and the objective parks, respectively. $\alpha$ ' and $\boldsymbol{\beta}$ ' are parameters. This model is a share estimation model, setting non-visitors, $G 0(j, k=0)$, as the baseline. The standard deviation of the stochastic term is defined by $\sigma^{V}=\sigma^{V}{ }_{1}\left(1+\mathbf{Z} \boldsymbol{\delta}^{V}\right)$, with the benchmark value $\sigma^{V}$ of site 1 and heterogeneity term $\mathbf{Z} \boldsymbol{\delta}^{\mathrm{V}}$, as in Eq. (1).

\subsection{Benefit value of the park}

After estimation of Eqs (1) and (3), mean WTP value at a certain distance is computed as follows for each $k$ th group.

$$
\operatorname{WTP}_{k}(L)=\int_{0}^{B_{\max }} \pi_{k}^{C}(B, L, \overline{\mathbf{X}}, \overline{\mathbf{Z}}) d B \times\left\{1-\pi_{k}^{C}\left(B_{\max }, L, \overline{\mathbf{X}}, \overline{\mathbf{Z}}\right)\right\}^{-1}
$$

Here again, $\pi_{k}^{C}(B, L, \overline{\mathbf{X}}, \overline{\mathbf{Z}})$ is the acceptance probability for proposed price $B$ by residents classified into the $k$ th group at a certain distance $L$, and is defined as Eq. (2). To calculate Eq. (4), $\mathbf{X}$ and $\mathbf{Z}$ were set as the mean value of data showing the typical resident, and $B_{\max }$ was the maximum price proposed in the questionnaire.

The WTP values in Eq. (4) are those for one household. As such, the benefits of a park can be calculated by the total WTP value totalled for the residents who stand to benefit. By using the function $N(L)$ for a number of residential households at distance $L$, two kinds of benefit value can be considered: the case of all residents for whom the benefit for the cost-benefit analysis is assumed to include the evaluation value of non-visitors as well as visitors; and the case of visitors for whom the benefit is assumed to exclude non-visitors and most nonuse value. Benefits of all residents, $T_{-} W T P_{\text {whole }}$, is:

$$
T_{-} W T P_{\text {whole }}=\sum_{k=0}^{3}\left[\int_{0}^{L^{*}}\left\{\pi_{k}^{V}(L) \times N(L) \times W T P_{k}(L)\right\} d L\right]
$$

Here, $\pi_{k}^{V}(L) \times N(L)$ corresponds to the total number of households classified into the $k$ th group at a certain distance. Benefit of only visitors, $T_{-} W T P_{\text {visitors }}$, is summed up from $k=1$ to $k=3$ in Eq. (5). 


\subsection{Data}

For estimation, concrete data including visitation frequency, contingent valuation answers, and attributes of residents were collected from 15 sites via questionnaire surveys. All parks were opened to residents several years before the survey. Terawaki [9] showed transferability in WTP functions of this kind of park among sites, so data from different sites are expected to be similar.

The questionnaire surveys were conducted in July 1999. Almost all examinees were randomly selected from a residential list of the local community. Questionnaires were then handed out to examinees by a representative of the local community and collected by mail from each site (Table 1). In sites 6 and 10 , the collection rates were lower than the others, but the rates of effective answers were acceptable because of low invalid response rates in these sites. Consequently, more than 100 responses were collected from each site, although this was insufficient for estimations at each site alone.

Effective data were composed by excluding residents, who disliked payments proposed instead of tax (protest zero respondents), and those, who agreed to enormous payments beyond our expectation from common sense (lexicographic respondents). This information was based on responses to additional questions about their reasons. On average, rates of protest zero and lexicographic respondents were about $40 \%$ of samples collected, showing almost the same rate as other studies in Japan.

Table 1: Outline of the questionnaire survey.

\begin{tabular}{lrl}
\hline \multicolumn{1}{c}{ Items } & \multicolumn{1}{c}{ Number } \\
\hline No. of research site & 15 & \\
Questionnaire sheets & 13,500 & $(900$ in each site $)$ \\
Distribution & 6,254 & $(213-639)$ \\
Collection & $46 \%$ & $(24 \%-71 \%)$ \\
Invalid responses & 867 & \\
Protest zero & 1,603 & \\
Lexicographic & 997 & \\
Effective Answers & $45 \%$ & $(28 \%-64 \%)$ \\
\hline
\end{tabular}

Note: Six sets of proposed prices were used in the questionnaire: $500 / 1000 / 250,1000 / 3000 / 500,3000 / 5000 / 1000,5000 / 10000 / 3000$, $10000 / 30000 / 5000$, and $30000 / 50000 / 10000$ yen/year $\left(B, B^{U}\right.$, and $B^{D}$, respectively).

\section{Results}

\subsection{Estimations}

Table 2 shows the estimation results of the WTP function in Eq. (1). Estimations of regional heterogeneity dummy were not shown in this table because all of 
them were insignificant. Good performances of most models are visible in the fraction of correct prediction and t-statistics for each variable. The effects of proposed price, $B$, were significantly negative in all groups. Each visitation group has the same tendency in effects of $B$.

Table 2: $\quad$ Estimations of the WTP Function in CVM.

\begin{tabular}{|c|c|c|c|c|c|}
\hline Variables & $\begin{array}{c}\mathrm{G} 3 \\
\text { fairly frequent }\end{array}$ & $\begin{array}{c}\text { G2 } \\
\text { frequent }\end{array}$ & $\begin{array}{c}\text { G1 } \\
\text { infrequent }\end{array}$ & $\begin{array}{c}\text { G0 } \\
\text { non-visitors }\end{array}$ & $\begin{array}{l}\text { All } \\
\text { groups } \\
\text { together }\end{array}$ \\
\hline \multirow[t]{2}{*}{ Constant } & 14.963 & 12.853 & 11.506 & 12.284 & 11.946 \\
\hline & $\left(5.5^{* *}\right)$ & $\left(4.8^{* *}\right)$ & $(6.1 * *)$ & $\left(7.2^{* *}\right)$ & $\left(11.8^{* *}\right)$ \\
\hline \multirow[t]{2}{*}{ Distance } & 0.015 & 0.040 & -0.013 & -0.023 & -0.032 \\
\hline & $(0.13)$ & $(0.7)$ & $(-0.9)$ & $(-1.0)$ & $(-2.5 * *)$ \\
\hline \multirow[t]{2}{*}{ Income } & 0.001 & 0.001 & 0.001 & 0.001 & 0.001 \\
\hline & $\left(2.9^{* *}\right)$ & $\left(2.6^{* *}\right)$ & $\left(2.6^{* *}\right)$ & $(3.2 * *)$ & $\left(5.6^{* *}\right)$ \\
\hline \multirow[t]{2}{*}{ Age $<40$} & -0.673 & 0.087 & -0.595 & -0.338 & -0.399 \\
\hline & $\left(-1.8^{*}\right)$ & $(0.3)$ & $(-3.2 * *)$ & $(-1.9 * *)$ & $(-3.7 * *)$ \\
\hline \multirow[t]{2}{*}{ Family } & -0.009 & -0.142 & 0.076 & 0.110 & 0.068 \\
\hline & $(-0.1)$ & $\left(-1.8^{*}\right)$ & $\left(1.7^{*}\right)$ & $\left(2.5^{* *}\right)$ & $\left(2.6^{* *}\right)$ \\
\hline Proposed Price & -1.930 & -1.654 & -1.555 & -1.757 & -1.639 \\
\hline$(B)$ & $\left(-5.6^{* *}\right)$ & $(-4.9 * *)$ & $\left(6.1^{* *}\right)$ & $(-7.3 * *)$ & $(-12.0 * *)$ \\
\hline No. of observ. & 259 & 399 & 835 & 1,294 & 2,787 \\
\hline Log likelihood & -364 & -552 & $-1,074$ & $-1,643$ & $-3,707$ \\
\hline$\chi^{2}$ of 0 slope & $65.9 * *$ & $133.5^{* *}$ & $324.0 * *$ & $391.9 * *$ & $888.4 * *$ \\
\hline $\mathrm{FCP}$ & 0.38 & 0.46 & 0.50 & 0.50 & 0.48 \\
\hline
\end{tabular}

The impacts of distance were insignificant in all groups, indicating that the WTP value itself does not change with distance. Distance was, however, highly significant in the case where all groups were mixed together, with a decreasing tendency in the WTP value. This inconsistency will be discussed in a later subsection.

Income had a positive effect in all cases, in accord with economic theory. The effects of Age were mostly negative, showing that the younger generation tended to rate the park at a lower value. Large families of infrequent visitors (G1) and non-visitors (G0) rated the park higher than small families. However, large families of frequent visitors, G3 and G2, were not different from small families. This is because festivals and events held in the park a few times a year serve the purposes of large families; the large families in non-visitors tend to consider future visits, evaluating the option value of the park.

Table 3 shows the estimation results of the gravity model in Eq. (3) on causative factors for heterogeneity in visitation frequency. 
Effects of distance decreased in the order $\mathrm{G} 3>\mathrm{G} 2>\mathrm{G} 1$ in absolute values. Distance influences frequent visitors in G3 more strongly than the other groups. The infrequent visitors in G1 are significantly influenced by distance, but quite weakly because residents visited the park a few times a year with less consideration of travel costs.

All values of constants, i.e., alternative specific constants (ASCs), were significant, indicating different effects between visitation groups. The negative ASCs indicate that probabilities for G3, G2, and G1 tend to be lower than for the non-visitation group (G0).

The impact of Income was positive for every group, and statistically significant only in G1. Since Income has an opposite sign from distance, they are substitute factors in terms of probabilities for visitation group. Age and Amusement facility differed in sign between groups. Age was negative in G3, but positive in the other groups, showing that younger residents tend to visit the park less frequently than older residents. The Amusement facility was negative in G2 and G3 because such facilities reduce visitation times except for G1. Only infrequent visitors may not be bored with amusement facilities.

Table 3: Estimations of the Gravity Model (Multinomial Logit Model).

\begin{tabular}{lrrr}
\hline \multicolumn{1}{c}{ Variables } & \multicolumn{1}{c}{$\mathrm{G} 3$} & $\mathrm{G} 2$ & $\mathrm{G} 1$ \\
& fairly frequent & \multicolumn{1}{c}{$\begin{array}{c}\text { frequent } \\
\text { infrequent }\end{array}$} \\
\hline Constant & $-0.659(-1.6 *)$ & $-1.660(-4.0 * *)$ & $-1.680(-5.5 * *)$ \\
Distance & $-2.700(-7.6 * *)$ & $-0.841(9.0 * *)$ & $-0.193(-5.0 * *)$ \\
Income & $8.77 \mathrm{E}-05(0.3)$ & $2.29 \mathrm{E}-04(1.0)$ & $5.00 \mathrm{E}-04(3.0 * *)$ \\
Age & $-0.422(-1.5)$ & $0.234(1.1)$ & $0.201(1.3)$ \\
Family & $0.204(3.0 * *)$ & $0.119(2.2 * *)$ & $0.110(2.8 * *)$ \\
Scale & $2.32 \mathrm{E}-05(4.8 * *)$ & $1.67 \mathrm{E}-05(4.1 * *)$ & $8.18 \mathrm{E}-06(3.4 * *)$ \\
Suburban area & $0.594(0.8)$ & $-0.214(-0.3)$ & $-0.499(-1.2)$ \\
Amuse & $-0.690(-1.8 *)$ & $-0.147(-0.5)$ & $0.283(1.5)$ \\
\hline Number of observations & 4,294 & Log likelihood & $-4,753$ \\
MacFadden R2 & 0.075 & $\chi^{2}$ of 0 slope & $768.2 * *$ \\
\hline
\end{tabular}

(Note) Site heterogeneity dummies were significant in site 2, 4, 5, 7, 10, 11, 12, and 13 , showing different standard deviation from site 1 .

\subsection{Benefit of the park}

Table 4 shows the mean WTP values per household for each visitation group calculated by Eq. (4), setting $L$ as the same average value of actual data for all groups. In these values, there is a decreasing tendency, G3>G2>G1>G0. Fairly frequent visitors evaluated the park most highly, followed by frequent visitors.

Visitation became less frequent with distance, as shown by the gravity model. Fairly frequent visitors were invariably from areas closer to the park, with a higher WTP value than infrequent visitors. Infrequent visitors visited the park 
from a farther distance, and had a low WTP value. Both effects were mingled in the all-groups-together case, giving a decreasing trend in the WTP value. If classification of visitation frequency is ignored in the CVM, a false tendency should therefore arise in the estimations.

Consider now the WTP value of a single visit, which is different from WTP values evaluated over all visitations in a whole year. When the WTP value was divided by the average number of visitation times in each group, the WTP value of a single visit tended to fall with increasing visitation frequency. The WTP value therefore has diminishing returns, in accordance with an increase in the number of visitations.

Table 4: $\quad$ Mean WTP values by visitation group at average distance.

\begin{tabular}{lrrrrr}
\hline \multicolumn{1}{c}{ Items } & G3 & G2 & G1 & G0 & Whole \\
$W_{\text {TPP }}$ (Yen/ household/ year) & 6,672 & 5,840 & 4,292 & 3,783 & 4,385 \\
& {$[5382-$} & {$[4862-$} & {$[3840-$} & {$[3447-$} & {$[4277-$} \\
[percentile 5\%-95\%] & $8958]$ & $8508]$ & $4709]$ & $4202]$ & $4802]$ \\
WTP per one visit (Yen) & 145 & 642 & 4,292 & & \\
$\pi^{\mathrm{V}}{ }_{k}$ for visitation group & 0.040 & 0.158 & 0.316 & 0.486 & 1.000 \\
\hline
\end{tabular}

Notes: 1. The value of WTP in 'Whole' row was calculated WTP value of 'All groups together' in Table 2.

2. The values of $\pi^{V}{ }_{k}$ were calculated by Eq. (3).

\subsection{Cost-benefit analysis}

Table 5 provides relations between the cost-benefit $(\mathrm{B} / \mathrm{C})$ ratio and beneficial zone to see stability in the cost-benefit analysis with CVM. The benefit of the total WTP values were calculated by integration with regard to $L$ until the certain distance point $L^{*}$.

From Table 5, the following features were observed. First, the benefit values calculated from all residents (the case using the whole sample) increased according to the area of the target zone for calculation. In other words, the benefit value of all residents depends strongly on the survey range decided a priori, even if the questionnaire sheets are distributed properly. The result of the cost-benefit analysis is no longer objective in this case, depending greatly on subjective premise of the researchers about the initial target range of investigation.

Second, the benefits calculated only from visitors' WTP (case of visitors) rose in the beginning and then after became constant at and outside of a certain point because the number of visitors comes close to zero at this point. Hence, the costbenefit analysis becomes stable, even if researchers set the area wider than the visitation range.

Third, benefit value of the TCM was 3,018 thousands yen calculated from the economic surplus value of a visit by the censored count data model with negative 
binomial distribution (Kunimitsu [6]). The $\mathrm{B} / \mathrm{C}$ ratio calculated from visitors' WTP corresponds closely to that calculated by the TCM (0.56). In contrast, the $\mathrm{B} / \mathrm{C}$ ratio calculated from all residents' WTP was much higher than that from the TCM because of the presence of non-use values such as existing value, bequest value, and option value of the park, which are probably valued by non-visitors. These non-use values are, of course, among the overall benefits, but there is a risk of over-estimation if the benefit values from all residents are used.

Fourthly, the $\mathrm{B} / \mathrm{C}$ ratio shows inefficiency in most sites if the benefit values were only calculated by visitors. Hence, planners might calculate benefit by evaluation values from all residents, placing excessive emphasis on the non-use value of the park. Even if maximum concession is included, the non-visitors outside of the feasible visitation zone should be excluded in the cost-benefit analysis. Because non-visitors from outside the zone evaluate the park without the use value, the maximum value of the $\mathrm{B} / \mathrm{C}$ ratio should be 2.05 for the average rural parks concerned here.

Table 5: $\quad$ Cost-benefit $(\mathrm{B} / \mathrm{C})$ ratio by distance.

\begin{tabular}{|c|c|c|c|c|c|}
\hline Items & $\mathrm{L}^{*}=5 \mathrm{~km}$ & $\begin{array}{c}\mathrm{L}^{*}=10 \\
\mathrm{~km}\end{array}$ & $\begin{array}{c}\mathrm{L}^{*}=15 \\
\mathrm{~km}\end{array}$ & $\begin{array}{c}\mathrm{L}^{*}=20 \\
\mathrm{~km}\end{array}$ & $\begin{array}{c}\mathrm{L}^{*}=25 \\
\mathrm{~km}\end{array}$ \\
\hline $\begin{array}{l}\text { No. of residents } \\
\text { (households) }\end{array}$ & 49,160 & 90,127 & 131,094 & 172,061 & 213,028 \\
\hline No. of visitors & 1,335 & 550 & 218 & 85 & 32 \\
\hline \multicolumn{6}{|l|}{ Benefits (1000 yen) } \\
\hline Case of whole & 5,631 & 8,388 & 10,961 & 13,373 & 15,640 \\
\hline Case of visitors & 3,299 & 3,613 & 3,734 & 3,780 & 3,797 \\
\hline Cost (1000 yen) & & & 5,346 & & \\
\hline \multicolumn{6}{|l|}{$\mathrm{B} / \mathrm{C}$} \\
\hline Case of whole & 1.05 & 1.57 & 2.05 & 2.50 & 2.93 \\
\hline Case of visitors & 0.62 & 0.68 & 0.70 & 0.71 & 0.71 \\
\hline
\end{tabular}

Notes: 1. Total number of households was assumed to be $N(L)=8193^{*} L$. This comes from actual number of households around 15 project sites.

2. Benefit values were calculated from $T \_W T P$ in Eq (5), and other benefits accounted for $1 / 3$ of the total costs. Social discount rate was assumed to be $4 \%$ and durable year of facilities was 35 years.

\section{Conclusion}

For better planning of rural parks, this paper evaluated the applicability of the contingent valuation method (CVM) by analysing the relation between benefits of a park and its visitation range. The $\mathrm{CV}$ model and the gravity model are used so as to show the affects of distance on willingness-to-pay (WTP) value. Heterogeneities by site and visitation frequency in cross-section data were taken into account in these models.

The results indicate that benefits evaluated by the WTP value decrease with distance, not because of a decreasing tendency in the WTP value itself, but 
because of a decline in visitation frequency influenced by distance. Benefits of all residents increased because of a rise in the number of non-visitors when the researchers set the survey range wider; however, benefits evaluated by visitors' WTP converged to a constant level at a certain range.

Therefore, the critical factor for applying the CVM to a cost-benefit analysis with stability is to exclude, or to control, the WTP value of non-visitors, especially non-visitors outside of the feasible visitation range.

\section{References}

[1] Bennett, J., Bueren, V. M. and Whitten, S. (2004) Estimating society's willingness to pay to maintain viable rural communities, The Australian Journal of Agricultural and Resource Economics 48 (3), 487-512.

[2] Hanemann, Loomis, J. and Kanninen, B. (1991) Statistical Efficiency of Double-Bounded Dichotomous Choice Contingent Valuation, American Journal of Agricultural Economics 73, 1255-63.

[3] Kaye-Blake, W., Bicknell, K. and Saunders, C. (2005) Process versus product: which determines consumer demand for genetically modified apples? The Australian Journal of Agricultural and Resource Economics 49 (4), 413-428.

[4] Kerr, G.N. (2000) Dichotomous choice contingent valuation probability distributions, Australian Journal of Agricultural and Resource Economics 44(2), 233-252.

[5] Kunimitsu, Y., Matsuo, Y., Tomosho, T. (2001) The Causative Factors about Contingent Valuation of Rural Park, and the Transferability of WTP Function (in Japanese), Journal of Rural Planning Association 20(1), 3140.

[6] Kunimitsu, Y. (2005) A Study on the Attractive Zone of a Rural Park in View of Usage Actions of Neighbouring Residents: Applicability of the Stochastic Choice Type Gravity Model to Location Planning (in Japanese), Journal of Rural Planning Association 23(4), 265-274.

[7] Kunimitsu, Y. (2006) Effects of Socio-institutional and Emotional Factors on Japanese Farmland Rental Transactions, Journal of Agricultural and Applied Economics 38 (1), 33-46.

[8] Talen, E. and Anselin, L. (1996) Assessing Spatial Equity: An Evaluation of Measures of Accessibility to Public Playgrounds, Environment and Planning 30(4), 595-613.

[9] Terawaki, T. (2001) Benefit Function Transfer in Agricultural Public Work (in Japanese), Journal of Rural Economics 71(4), 158-160.

[10] Yoshida, K., Kinosita, J. and Egawa, A. (1997) Valuing Economic Benefits of Agricultural Landscape by Double-Bounded Dichotomous Choice CVM (in Japanese), Journal of Rural Planning Association 16(3), 205-215.

[11] Willis, K.G. (1998) A Review of Cost-Benefit Analysis as Applied to the Evaluation of New Road Projects in the U.K., Transportation Research Part D 3(3), 141-156. 